\title{
An Investigation of Factors that Inform Green IT Practices in the North West Provincial Government of South Africa
}

\author{
Lucia Letlonkane \\ Information Systems Programme, School of Economics \& Decision Sciences, \\ North West University, Private Bag X2046, Mmabatho, 2735, South Africa \\ Lucia.letlonkane@nwu.ac.za \\ Nehemiah Mavetera \\ Information Systems Programme, School of Economics \& Decision Sciences, \\ North West University, Private Bag X2046, Mmabatho, 2735, South Africa \\ Nehemiah.mavetera@nwu.ac.za
}

\section{Doi:10.5901/mjss.2014.v5n20p163}

\begin{abstract}
The effects of global climate change have been a major topic of discussion in the Information Technology (IT) industry in recent times. The IT sector has been regarded as one of the sectors contributing significantly towards climate change. This is due to the negative effects associated with the generation of heat and carbon emissions from IT equipment such as computers and servers. Environmental issues especially the reduction of global warming is gaining a lot of attention from organisations across the globe. Therefore, Greening the IT environment is seen as part of the solution to addressing this problem. The purpose of this study was to investigate the factors that inform Green IT practices in the North West Provincial Government (NWPG). The study focused on three departments which fall under the IT section of the Department of North West Provincial Treasury. The study followed a quantitative descriptive type of research study, where questionnaires were used to collect the data. The research results indicate that while there is an appreciation of the importance of bringing in Green IT practices in the government sector, the organization, suppliers, employees and regulations should synergically be organized to reap the benefits of Green IT. For example, less use of printing power, introduction of power management systems, adopting Green IT infrastructure and formulating regulatory green environmental policies, their use and subsequent monitoring can heavily improve their adoption of Green IT practices.
\end{abstract}

Keywords: Information Technology (IT), Green IT, Environment, Global warming, IT practices.

\section{Introduction}

The topic of Green IT has been gaining increased attention of researchers, practitioners and policy-makers. This is partly due to increased concerns about environmental safety and partly because of tremendous levels of increased usage of all kinds of computer-based systems. The impact of IT operations on the environment has raised awareness of Green IT in many organisations.

According to Molla (2008), the environmental impact of IT operations is a two-way street. It is not limited to the disposal of IT equipment only (such as computers and printers), but it also includes the provision of service. Technology and IT have not always worked to the benefit of environmental sustainability (McCabe 2008). The adoption of IT is usually motivated by the potential economic benefits of using technology (Molla, Cooper \& Pittayachawan 2009).

Many organisations have come up with different views on how Green IT will benefit them by saving costs and the environment. To many people, Green IT is about reducing the energy consumption and carbon footprint of the IT function within the organisation (Murugesan 2008). Therefore it makes sense, as emission reduction becomes appropriate and even compulsory, that IT companies and the government sector should look at ways of reducing the energy consumption of their systems.

Nowadays Green IT is a growing concept for many organisations, researchers and IT practitioners, so this paper focuses on some key areas that needs to be addressed when adopting Green IT. The background of the study is presented in the next section; followed by literature review. The literature review will first look at the definitions of Green IT because there seems to be a gap in how different researchers and practitioners understand the definition of Green IT. 
The paper will then look at the impact that IT has on the environment and the benefits of Green IT. The research methodology and design will follow, which will lead us to the discussion of the analysis and results.

\subsection{Background and context}

This study focused on the North West Provincial Government (NWPG) in Mafikeng. The North West Provincial Government is the government of the North West Province. The North West Province is one of nine provinces in South Africa. Its capital is in Mafikeng. The majority of the residents in the province are black people who speak Setswana. The provincial government (NWPG) has different government departments. Most of the head offices of the departments are situated in Mafikeng in the Garona Building.

The study was done with reference to three departments: Provincial Treasury, the Premier's Office and Education. These departments have a centralised IT (information technology) section that services them all. The IT section is responsible among other things for setting up the network, installing applications on new computers, connecting the computers to the network and removing old computers from the network. Hence, all IT-related work is done by the IT department.

\section{The Impact that Acquisition, Use and Disposal of IT Resources has on the Environment}

Information Technology has changed our society remarkably over the past years. Although its effects on our everyday lives are obvious, the effect that it has on the environment has been ignored in the past years (Piccirillo 2011).Computer use in the government sector is an important aspect of everyday life; however, their impact is not entirely realised or mainly considered (Murugesan 2008).As the debate on climate change and its associated effects continues, society is becoming more aware of the negative effects businesses can have on the environment.

Due to the constant changes in the industry, new advanced devices and computers are being produced continuously (Kurp 2008). The manufacturing of these products becomes a problem to the environment due to different chemicals and materials used. Most of these materials are a hazard to the environment (Piccirillo 2011). Some elements used in the manufacturing process are toxic and harmful to the environment too (Murugesan 2008).

IT investors and consumers measure the carbon footprint of an IT company and IT products by looking at the total greenhouse emissions that are caused by individual organisations' operations or products directly or indirectly (Kurp 2008). Organisations must be aware of all these toxic elements before purchasing computers. The environmental information must be made available by these manufacturers to their buyers.

The number of computers used in the government sector is increasing due to their frequent replacement (McCabe 2008). This has brought a lot of challenges especially in terms of massive energy requirements to power and cool them. This issue makes the environmental impact of IT a major concern. The total electrical energy consumption by servers, computers, monitors, data communications equipment, and cooling systems for data centres is steadily increasing (McCabe 2008).

A study that was done by Bournay (2008) has shown that computers and other IT resources are the largest sources of growth in electricity demand in commercial and government buildings. A typical medium-sized personal computer consumes about 150 Watts of electricity per hour. This pushes the electricity usage high, especially in a situation where computers are not switched off after use. Unlike privately-owned PCs, workstations and network servers in the offices are often left idling.

The research conducted by Vreeswijk (2008) has also shown that every 3 to 5 years, organisations replace their computers with newer ones. The older computers are discarded and thrown away at landfills and this becomes a significant problem to the environment (McCabe 2008). However, Vreeswijk (2008) hinted that there are measures of prevention that can help in the reduction of this contaminant process that harms the environment.

According to McCabe (2008), users of computers increase every year as companies, including the government, hire more staff. This results in an increase in IT infrastructure capacity because customer demands increase (Harris 2008). McCabe further emphasizes that energy is not a concern for most IT departments since the energy bill is being paid by someone else. The main concern of these departments is to ensure that IT infrastructure runs, not that it is energy-efficient (Williams \& Madison 2010).

In the IT space, the disposal of equipment is a major environmental problem because of the toxic products in computers and displays (Winston 2010). However, according to Junglas and Watson (2006) IT has been the major contributor to productivity growth in many countries over the last half century. Green IT has been seen as a solution to most of the challenges that have been mentioned. 
The problem therefore is that many activities that are practised in the government sector affect the environment in a negative way as there is no Green IT policy implemented. In many such environments, the IT users neither appreciate the negative effects of IT use to the environment nor conversely, the factors that inform the practice of a green IT environment.

\section{Green IT Definitions}

The Green IT concept comprises two building blocks, viz. green and information technology. The green in Green IT refers to the environmentally sustainable application of Information Technologies. In another context green is to be understood in relation to the environmental problem of climate change and emission of greenhouse gases (Murugesan 2008).

Molla (2009) explains Information Technology as computer-based information systems, particularly software applications and computer hardware. Molla further explains it by emphasizing that it is seen as the application of computer, communications and software technology to the management, processing and dissemination of information.

Murugesan (2008) defines Green IT as "the study and practice of designing, manufacturing, using, and disposing of computers, servers, and associated subsystems including monitors, printers and storage devices, efficiently and effectively with minimal or no impact on the environment". He also mentions that Green IT is multi-faceted and encompasses the manufacturing and purchasing of energy efficient IT equipment, the efficient operation and utilization of hardware devices, as well as its proper disposal. Esty and Winston (2008) on the other hand defined Green IT as the design, production, operation, and disposal of ICT and ICT-enabled products and services in a manner that is not harmful and may be positively beneficial to the environment.

The IT resources lifecycle from manufacturing, usage and disposal poses an environmental threat (Esty \& Winston 2008). Green IT is the term used to promote this awareness. It also helps to study the potential ways to solve the problems with regard to pollution and consumption of vast amounts of energy in the computing world (Baroudi et al.2009).

Other authors, like Li and Zhou (2011), came up with a very detailed explanation of Green IT. According to them, Green IT is a global concept that entails systems architecture, systems software, and parallel and distributed computing and computer networks. It aims to reduce the power consumption of computer systems, provide high-efficient, dependable and pervasive services, and achieve the objective of low power usage of IT systems.

Accordingly, Molla (2008) states that Green IT is not a well-defined concept or a uniformly accepted set of practices. In many associated literatures, it is associated with technologies and attempts to reduce power usage, cooling and real estate costs (Rasmussen 2006). Molla et al. (2009) came up with two themes that highlight the problem as well as solve it at the same time. These themes cover the IT life cycles, and also include both the hardware and software technologies.

In conclusion, Molla (2008) then defines Green IT as "an organization's ability to systematically apply environmental sustainability criteria to the design, production, sourcing, use and disposal of the IT technical infrastructure as well as within the human and managerial components of the IT infrastructure". Chen et al (2008) on the other hand believe that the manner in which customers and the public view an organisation must be carefully monitored as it relates to the environment and the use of natural resources and energy.

\subsection{Reasons and benefits for adopting Green IT}

Adopting green IT practices offers businesses and individuals financial and other benefits. IT operations achieve better energy efficiency through green initiatives, which in turn financially benefit them, especially when electrical energy is at a premium and energy prices are rising (Murugesan 2008).

There is a long list of benefits of Green IT, among which list, reducing power consumption and lowering energy cost are at the top (Molla 2008). Most companies' priorities when it comes to environmental issues are cost control and energy efficiency measures.

The research that was done by Gadenne \& Kennedy (2009) indicates that there are two major categories of benefits: environmental benefits and cost-reduction benefits associated with Green IT. From an organisational perspective, Green IT provides the capability for organisations to reduce the footprint of IT equipment, manage the profiling of the enterprise's footprint, provide measures to reduce the enterprise's footprint, provide measures to reduce the value chain footprint and provide measures to operate in a low carbon economy (Dick \& Burns 2011).

Usually, power management tools are known to automatically decrease power without sacrificing the performance of a computer (Molla 2008). Furthermore, notebook computers operate much more efficiently than desktop computers, as they are designed to run on battery power (Murugesan 2008). This means that notebooks offer a good solution to reduce 
power and carbon emissions associated with end-user equipment. Although not suitable for all situations, more and more organisations are choosing notebooks over desktops. An added advantage of notebooks is that, many workers prefer carrying them home and this compels them to switch off their notebooks after work unlike if they use desktop computers. This in turn provides organisations with the added benefits of a more productive, flexible and mobile workforce.

Multi-function devices are also a great way to reduce power consumption and carbon emissions within the office (Kurp 2008). They provide the ability to minimise standby power and maximise equipment utilisation by replacing 'standalone' printers, photocopiers, facsimiles and scanners with a single device (Kurp 2008).

Energy management policies provide the ability to monitor and control how IT equipment behaves under specific situations. As such, energy management policies are either built into IT equipment or provided separately as software packages (McCabe 2010). This can range from deactivating screen savers, automatically putting computers into hibernate mode during idle periods, automatically shutting down during out of office hours or installing a kill switch. While this provides direct cost savings to an organisation's power bill, organisations also benefit by lowering the carbon footprint associated with the operation of IT equipment (Ryan 2008).

Companies still spend lots of money on office space, some of which is occupied by document-filled file cabinets and its associated lighting, heating, and cooling costs even in this electronic age. Improving content management processes, including content storage, can help lower these costs (Newell 2010).

Companies can eliminate many direct and indirect costs by optimizing document processing and management. For example, eliminating single-sided printing alone can dramatically cut carbon and energy costs (Newell 2010). Printing important information directly on a customer's bill can also cut paper volume and its associated production, handling, and delivery costs, while increasing efficiency and reducing resource demand (Newell 2010).

Green IT can contribute to the reduction of printing costs, level of waste and pollution through practices such as PC power management, server management, recycling, socially responsible throwing away of old technologies and sourcing from green vendors (Boudreau et al. 2008). For IT maintainability and support, Green IT shows that IT can enable an organisation's sustainable practice by providing methodical or analytical tools for carbon footprint count (Molla et al. 2008). This is allowing or bringing forward the logical and investigative tools that can be used to calculate the printing costs, the energy consumption costs and other related IT costs.

While most of the previous sections discuss several issues that have been cited from extant literature about the positive and negative effects of practicing Green IT, very little however, has been said about the questions that are raised by the problem of not understanding these effects. This is also viewed from the angle that Greening the IT environment is a new concept especially in developing countries and NWPG is one environment in such a country. The research study focused on two questions, that is:

- What impact does the use of IT resources have on the environment?

- How will IT departments benefit from adopting Green IT practices when acquiring, using and disposing IT resources?

The next section discusses the theoretical framework that informed this study.

\section{Theoretical Framework}

A theoretical framework can be conceived of as the structure that supports the theory of a research study. It must demonstrate an understanding of concepts that are related to the topic in a broader way (Punch 2005). The theoretical framework has been developed to highlight factors that can be used by organisations like the government sector in implementing Green IT. After studying several Green IT frameworks (Connection Research 2008; Molla \&Cooper 2009), a conceptual green IT framework was proposed that depicts factors that are important when considering the adoption of Green IT practices in the government sector. Figure 1 shows this proposed conceptual framework. 


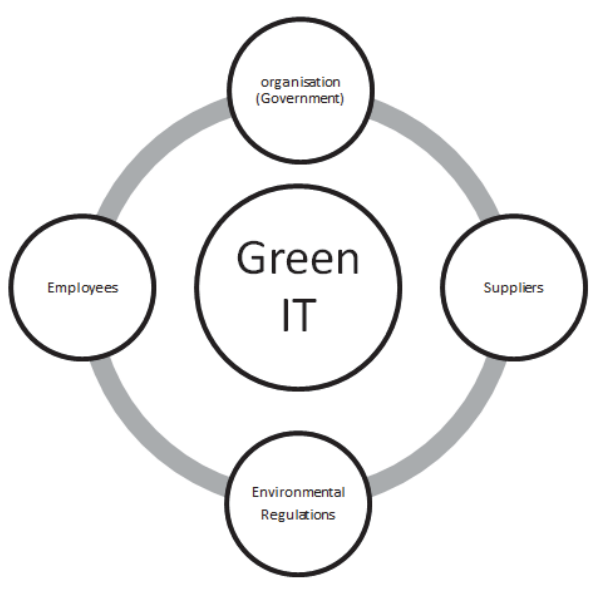

Figure 1: A conceptual framework for implementing Green IT practices

\subsection{Organisation}

The current literature on Green IT has shown that organisations can become involved in changing and shaping IT policies and ensuring that they reduce the organisations' carbon footprint (Winston 2008). Most of the organisations experience a need to become more environmentally friendly (Lamb 2009). This can only be possible if CIOs and IT managers have a positive attitude on the benefits that Green IT will bring to the organisation.

Any organisation must have a plan on how they intend to ensure the successful adoption of Green IT practices. Managers and $\mathrm{ClOs}$ must ensure that they take into consideration the activities and initiatives that reduce the negative environmental impacts that IT have (Lamb 2009). They must also play roles in ensuring that they drive the efficiency in the IT organisation by identifying green strategies; find green technology solutions that enable the business plan as a way of supporting and implementing green initiatives (Murugesan 2008).

\subsection{Employees}

Murugesan (2008) maintains that Green IT awareness must spread among IT professionals and employees. He further mentions that employees need to be educated about green IT practices and knowledge thereof shared in the organization on how to become green. Users of IT resources must also be trained on how to use them in a greener way (Lamb 2009). They also need to be made aware of how IT could contribute towards a friendly environment

Most of the employees need training on issues that are related to Green IT. Changing the way in which they operate and handle their end-user devices will reduce the organisation's energy consumption. Organisations seeking to implement Green IT practices need to encourage their staff to come up with new and greener solutions as a way of involving them (Unhelkar 2011). This means that the success of adoption of Green IT practices also depends on employee commitment and positive attitudes towards Green IT.

\subsection{Suppliers}

Suppliers also play an important role in the implementation of Green IT practices in an organisation (Murugesan 2008). Unhelkar (2011) agrees that end-user devices are one of the IT resources that contribute towards the high energy consumption in organisations. According to Lamb (2009) organisations must focus on properly selecting and evaluating suppliers before they purchase IT resources or equipment.

Organisations like the government sector can choose to buy products that are environmentally built and with an eco-friendly label. There are several types of eco-labels for IT resources. These labels include the Energy Star and the TCO (Unhelkar 2011). This will help organisations control the asset life cycle from the beginning to the end. The reason to improve IT asset life cycle is one of the benefits why organisation must choose suppliers that are selling environmentally-friendly equipment (Lamb 2009). 


\subsection{Environmental regulations}

The literature on Green IT has shown that there is increased pressure on organisations to improve and eliminate their carbon emission (Murugesan 2010). Some governments such as the Australian government are forcing companies to make a report on their carbon emission every year (Unhelkar 2011). This becomes a challenge to many organisations because this comes from the environmental authorities.

Environmental regulations are one of the factors that will ensure that companies adhere to policies that govern the use of IT resources (Molla 2009). This will contribute towards the success of Green IT adoption and implementation as it will ensure the reduction of carbon footprint from organisations (Murugesan 2008).

\section{Research Methodology}

This study assumed a quantitative research methodology. A quantitative research methodology is defined as a study approach that is based on the measurement of quantity or amount (Durrheim 2006). It gathers numeric data and datacollection techniques such as surveys are employed. Statistical techniques are applied to analyse the data (Coldwell \& Herbst 2006). The study was conducted at the Garona Building of the North West Provincial Government in Mafikeng. Three sections that are serviced by one central IT department based in the Provincial Treasury were surveyed.

Using simple random sampling techniques, questionnaires were distributed to one hundred and fifty (150) individuals at these departments. A simple random sample was used because it offers each member of the population an equal chance of being included in the sample. Also, each sample of a particular size has the same probability of being chosen. The questionnaire addressed issues such as awareness of Green IT, the impact of IT use on the environment and benefits of adopting Green IT. Of the one hundred and fifty (150) questionnaires distributed, one hundred and nine (109) were completed and returned. This gave a return rate of 73\%. The data was then analysed using SPSS version 21 software. It must be noted that this research study is one example of descriptive statistics applications.

\section{Data Analysis and Results}

\subsection{Responses}

The results on table 1 indicates that majority of the respondents were females.

Table 1: gender of the participants

\begin{tabular}{|c|c|}
\hline Gender & Percentages of responses \\
\hline Male & 44 \\
\hline Female & 56 \\
\hline
\end{tabular}

Table 2 reflects that the majority of the respondents are Blacks. The survey was done in Mafikeng. As it was mentioned earlier in the study, Mafikeng, the capital, is situated in the North West Province. The province is one of the 9 provinces in South Africa. It is mostly inhabited by black people who speak Setswana

Table 2: Race of participants

\begin{tabular}{|c|c|}
\hline Race & Percentages of responses \\
\hline Black & 87.2 \\
\hline White & 0.9 \\
\hline Coloured & 7.3 \\
\hline Indian & 4.2 \\
\hline
\end{tabular}

Table 3 shows the academic qualifications of all the sampled participants whose data was written and captured. The knowledge of qualifications assisted the researchers in checking the suitability of the respondents to measure the constructs included on the research instrument.

Table 3: Qualifications of participants 


\begin{tabular}{|l|c|}
\hline \multicolumn{1}{|c|}{ Qualification } & Percentages of responses \\
\hline Below Grade 12 & 16.5 \\
\hline Grade 12 & 13.8 \\
\hline Graduate & 45.9 \\
\hline Post graduate & 23.9 \\
\hline
\end{tabular}

The majority of the respondents on this section are graduates from tertiary institutions. From the 109 responses received, 23.9\% are respondents holding post-graduate qualifications. This implies that the majority of the participants are educated. One can infer that majority of these respondents understand the effects of global warming and therefore, the impact their organizational IT practices may have on the organization

Table 4: Job level of participants

\begin{tabular}{|l|c|}
\hline \multicolumn{1}{|c|}{ Job Level } & Percentages of responses \\
\hline Entry level & 24.8 \\
\hline Lower level & 26.6 \\
\hline Middle level & 40.4 \\
\hline Senior level & 8.2 \\
\hline
\end{tabular}

Majority of the respondents are those that are the middle level and minority are respondents at the senior level.

Table 5: The impact of IT use on the environment

\begin{tabular}{|c|c|c|c|c|c|c|}
\hline Statement & $\begin{array}{c}\text { Completely } \\
\text { agree }\end{array}$ & Agree & Neutral & Disagree & $\begin{array}{c}\text { Completely } \\
\text { disagree }\end{array}$ & $\begin{array}{c}\text { Majority Agree/ } \\
\text { disagree }\end{array}$ \\
\hline Are you aware of global warming? & 71.6 & 19.3 & 4.6 & 4.6 & 0.0 & Agree \\
\hline $\begin{array}{l}\text { Do all employees who need computers use them the whole } \\
\text { time? }\end{array}$ & 61.5 & 21.1 & 12.8 & 3.7 & 0.9 & Agree \\
\hline Does the use of computers contribute to climate change? & 40.4 & 17.4 & 38.5 & 2.8 & 0.9 & Agree \\
\hline Are computers harmful to the environment? & 34.9 & 21.1 & 30.3 & 13.8 & 0.0 & Agree \\
\hline $\begin{array}{l}\text { Do computers and office equipment play a large role in energy } \\
\text { consumption? }\end{array}$ & 51.4 & 29.4 & 16.5 & 2.8 & 0.0 & Agree \\
\hline Do employees use a lot of paper for printing on a daily basis? & 69.7 & 18.3 & 8.3 & 2.8 & 0.9 & Agree \\
\hline The use of papers and their disposal harm the environment & 61.5 & 22.0 & 12.8 & 1.8 & 1.8 & Agree \\
\hline
\end{tabular}

This section addresses the impact that the use of IT resources has on the environment. The survey also gauged the beliefs of participants regarding the position of IT whether it is causing or resolving the environmental sustainability problems.

Out of the 109 responses received, $90 \%$ agree that they are aware of global warming and many respondents (57.8\%) agree that the use of computers contributes to climate change but $38.5 \%$ are neutral.

Even though many believe that the use of computers and computing equipment contributes to global warming and climate change, many employees still leave their computers on even when not in use. The heat generated by these computers contributes towards climate change.

From the 109 responses received, $80.7 \%$ agree that computers and other office equipment play a large role in energy consumption. Other office equipment that the study is referring to is servers, air conditioners or any other cooling system and printers.

The study also investigates the use of paper in the government offices. From the 109 responses received, $88.1 \%$ agree that a lot of paper is being used by employees on a daily basis for printing. Printing of documents still takes place on a daily basis, reports are still printed and archived. Many participants of this study believe that at the end of use; those papers are disposed of or thrown away in landfills which will become a challenge for the environment. If paperless offices were to be implemented, it could reduce the amount of paper used and disposed of. 
Table 6: Benefits of Green IT

\begin{tabular}{|l|c|c|c|c|c|c|}
\hline \multicolumn{1}{|c|}{ Statement } & $\begin{array}{c}\text { Completely } \\
\text { agree }\end{array}$ & Agree & Neutral & Disagree & $\begin{array}{c}\text { Completely } \\
\text { disagree }\end{array}$ & $\begin{array}{c}\text { Majority } \\
\text { Agree/disagree }\end{array}$ \\
\hline Will paperless offices reduce the use of paper and cartridges/ink? & 61.5 & 22.0 & 8.3 & 6.4 & 1.8 & Agree \\
\hline $\begin{array}{l}\text { Acquisition of computers with green procurement strategies can } \\
\text { potentially reduce their environmental burden }\end{array}$ & 49.5 & 24.8 & 23.9 & 1.8 & 0.0 & Agree \\
\hline Does your computer switch itself off when not in use? & 55.0 & 22.0 & 7.3 & 10.1 & 5.5 & Agree \\
\hline Will switching off computers when not in use reduce electricity? & 60.6 & 20.2 & 15.6 & 3.7 & 0.0 & Agree \\
\hline Will reducing servers in the organisation benefit the environment? & 36.7 & 20.2 & 33.9 & 5.5 & 3.7 & Agree \\
\hline $\begin{array}{l}\text { Recycling and re-using papers and computers will reduce their } \\
\text { number during disposal }\end{array}$ & 52.3 & 31.2 & 13.8 & 1.8 & 0.9 & Agree \\
\hline
\end{tabular}

Out of 109 responses received, $83.5 \%$ agree that paperless offices will be beneficial; $8.3 \%$ are neutral and $8.2 \%$ disagree. The majority of our respondents agreed that paperless offices will reduce the use of paper and the ink for printing.

On the issue of acquisition of computers with green procurement strategies, the responses were as follows: $74.3 \%$ of the 109 questionnaires received agree. This suggests that majority of the respondents agree that the acquisition of these computers can reduce their environmental burden.

One of the benefits of Green IT is that when computers are not in use, they must be switched off to reduce the electricity usage. The majority of the respondents, $80.7 \%$, agree and $77 \%$ of the respondents also agree that if computers use power management tools that help the computers to switch themselves off when not in use, this will also save electricity.

Reduction of servers in the organization will benefit the environment as servers use a lot of energy and there is also a lot of electricity that is used on air-conditioners that are used to cool them. The study shows that $56.9 \%$ of the respondents agree.

\section{Research Findings}

The purpose of this study was to investigate factors that inform Green IT practices in the NWPG (North West Provincial Government). Two questions were asked that are related to the problem statement of the research. Referring to the first question, that is: "What impact does the use of IT resources have on the environment?"

The research findings indicate that the use of computers contribute towards global warming, many employees use computers on a daily basis, and that there is a large number of paper being used for printing purposes.

On the second question, that is: "How will IT departments benefit from adopting Green IT practices when acquiring, using and disposing IT resources?"

The majority of respondents agreed that paperless offices will be beneficial as it will reduce the use of paper in the government sector. Paper printing costs money, excessive power usage, and in turn cutting of trees hence contributing to the negative effects of IT to the environment. Furthermore, most of the respondents agreed that acquiring computers with green procurement strategies can potentially reduce their environmental burden. Organisations need to buy equipment that are energy efficient and must ensure that equipment include LCD monitors, wireless networks, and printers with double-side printing functions, multifunction devices, rechargeable devices and equipment complying with energy safe mode standards among other things.

\section{Recommendations and Conclusions}

The Green IT literature indicates that one of the practices that organisations can implement when trying to save energy costs will be to switch off computers when not in use. The study indicates that $80.7 \%$ of respondents agree that switching off computers will reduce the energy usage.

There are some power management tools that may be implemented and used as activating power management features or adjusting the properties of electronic devices to save energy will aid in achieving this purpose. The adjustment includes setting the hibernating mode, applying blank screensavers and reducing screen brightness.

Recycling and re-using of computers and other equipment is one of the practices associated with Green IT. The study indicates that $83.5 \%$ of the respondents agree that recycling computers and reusing them will save cost and reduce e-waste. They also agree that reducing the use of paper will reduce the volume during disposal.

The literature has indicated that many organisations are moving towards paperless offices and some have adopted 
the double printing system. The use of emails and electronic files is very convenient in many organisations as it has reduced printing of documents which in return needs storage after use. IT departments will benefit more on saving costs while on the other hand trying to reduce the impact of IT use on the environment.

Most of the literature on Green IT and Green IS has shown that the process of implementing Green IT/IS requires changes from older models to newer models. Therefore, companies should develop an organization's business readiness to adapt to new processes. The business readiness includes various elements such as policy and procedures, business goals, systems and infrastructure, training, etc.

Cloud computing can help organisations of all sizes to go green by providing a shared and on-demand infrastructure with virtualisation capabilities (Lamb 2009). This will mean that organisations will access services and infrastructure on an as-needed basis, and promote the ability to promote distributed workforce.

\section{References}

Baroudi, C., Hill, J., Reinhold, A. \& Senxian, J. (2009). Green IT for dummies, For Dummies. London: Wiley,

Boudreau, M.C., Chen, A. \& Huber, M. (2008) .Green IS: Building sustainable business practices, Information Systems: A Global Text Project. Athens.

Bournay, E. (2008). Life cycle emissions of a computer, UNEP/GRID-Arendal Maps and Graphics Library, July 5 .2008. IBM Press.

Coldwell, D. \& Herbst, F. (2004). Business Research. Cape Town: Juta Co. 148p.

Dick, G.N., \& Burns, M. (2011). Green IT in small business: an exploratory study. Proceedings of the SAIS Conference Atlanta, GA, USA.

Durrheim, K. (2006). Research Design. (In Terre Blanche, M., Durrheim, K. \& Painter, D. Eds. Research in practice: applied methods for the social sciences. (2nd ed). Cape Town: Juta Co. 12:10,11

Esty, D. C. \& Winston, A. S. (2006). Green to Gold: How Smart Companies Use Environmental Strategy to Innovate, Create Value, and Build Competitive Advantage. New Haven: Yale University Press.

Gadenne, D. L. \& Kennedy, J. (2009). An empirical study of environmental awareness and practices in SMEs. Journal of Business Ethics, 84(1), 45-63.

Harris, J. (2008). Green Computing and Green IT Best Practices on Regulations and Industry Initiatives, Virtualization, Power Management, Materials Recycling and Telecommuting, ICIS 2008 Proceedings.

Junglas, I. A. \& Watson, R. T. (2006). The U-Constructs: Four Information Drives. Communications of AIS, (17), 569-592.

Kurp, P. (2008). Green Computing. Communications of the ACM, 51(10).

Lamb, J. (2009). The Greening of IT: How Companies Can Make a Difference for the Environment. Boston: IBM Press.

Li, Q. \& Zhou M. (2011).The Survey and Future Evolution of Green Computing. ACM International Conference on Green Computing and Communications, IEEE 2011.230-233.

McCabe, L. (2008).What is Green IT and why should you care, 5 (10). [Online] Available: http://www.smallbusinesscomputing.com Itestdrive/article.php/3855806/What-Is-Green-IT-and-Why-Should-You-Care.htm.

McCabe, L. (2010). What is Green IT and why should you care, 7(15). [Online] Available: http://www.smallbusinesscomputing.com Itestdrive/article.php/39/What-Is-Green-IT-and-Why-Should-You-Care.htm. Last accessed 02 March 2013.

Mitchell, R.L. (2008). "Green by Default", ComputerWorld. [Online] Available: http://www.computerworld.com/pdfs/LFG_green_IT_2008. pdf. Last accessed 23 November 2012.

Molla, A. (2008). GITAM: A Model for the Acceptance of Green IT.19th Australasian Conference on Information Systems, Christchurch, New Zealand.

Molla, A. Cooper, V. \& Pittayachawan, S. (2009). IT and Eco-Sustainability: Developing and Validating a Green IT Readiness Model, Thirtieth International Conference on Information Systems, Phoenix, Arizona, USA, Dec. 15- 18.

Molla, A. (2008). Exploring the Extent of Green IT Adoption and its Driving and Inhibiting factors, Journal of Information Science and Technology, 6(4):5.

Murugesan, S. (2008). Harnessing green IT: Principles and practices.IT professional, 10(1): 25-26.

Newell, R. (2010).Realising the financial and environmental value of Green IT.WIS Publishing,

Philipson, G. (2010).Carbon and Computers in Australia: The Energy Consumption and Carbon Footprint of ICT Usage in Australia, Australian Computer Society. Australia.

Picirillo, N. (2011).IT Going Green: Forces Pulling in Different Directions. Financial Times, 30 May.

Punch, K.F. (2005). Introduction to social research: quantitative and qualitative approaches. (2nd ed). London: Sage publications.

Ryan, A. (2008).From Green IT to Green IS. Cutter Bench Journal, 21(2):6-12.

Unhelkar, B. \& Dickens, A. (2008). Lessons in Implementing 'Green' Business Strategies with ICT, Cutter IT Journal, 21(2), 32-39.

Unhelkar, B. (2011).Green IT Strategies and Applications - using environmental intelligence. Boca Raton, FL, USA: Taylor \&Francis Group, LLC.

Vreeswijk, J. (2008).Opportunities in Lean, Green and Sustainable IT. Green IT Tools [Online] Available: http://www.greenittools.com/ article/opportunities-lean-green-and-sustainable-it.

Williams, C. \& Madison, A. (2010). Corporate climate, The Green media ROI experts. IEEE Xplore, (7)3. 